\title{
De la ciudad enferma. Platón e Hipócrates
}

\author{
About the ill city. Plato and Hippocrates \\ Julián D. Bohórquez CarvajaL* \\ Pontificia Universidad Javeriana, Bogotá Colombia. bohorquez.julian@javeriana.edu.co
}

Recibido El 19 dE JULIo de 2020, APROBAdo El 30 DE AGosto de 2020

\begin{abstract}
RESUMEN
Exploro la influencia de los Tratados Hipocráticos en la República de Platón, con énfasis en el papel de nociones provenientes de la llamada teoría humoral de la enfermedad. Primero, analizo la importancia de los conceptos de "ciudad inflamada" y "sedición" (stasis) en el texto del filósofo ateniense, y sus relaciones con la ciencia médica de su tiempo. Luego, señalo el papel de la dietética hipocrática en algunos argumentos consignados en la República, para entonces abordar la lectura filosófica, presente en esta obra, del principio médico conocido como "la curación por lo semejante". Finalmente, indago sobre diversas analogías significativas entre las tesis de la escuela de Hipócrates, en relación con el tratamiento de las enfermedades, y la propuesta platónica de una "curación de la ciudad".
\end{abstract}

\section{Palabras Clave}

Platón, Hipócrates, Tratados Hipocráticos, República de Platón, Teoría humoral.

\begin{abstract}
In this paper I explore the influence of the Hippocratic Treaties on Plato's Republic, emphasizing on the role of notions from the so-called Humoral theory of the disease. First, I analyze the importance of the concepts of 'swollen city', and 'sedition' (stasis) in the work of the Athenian philosopher, and its relations with the medical science of his time. Second, I point out the role of the Hippocratic dietetic in some arguments stated in the Republic, to subsequently address its philosophical reading of the medical principle known as "healing by means of the similar". Finally, I inquire about various significant analogies between the theses of the school of Hippocrates, in relation to the treatment of diseases, and the Platonic proposal of a "cure for the city".
\end{abstract}

\section{KeYwordS}

Plato, Hippocrates, Hippocratic Treaties, Plato's Republic, Humoral theory.

* (iD orcid.org/0000-0003-2371-4535 Google Scholar 


\section{Introducción}

Este ensayo explora algunos vasos comunicantes entre la República de Platón y la medicina de su tiempo; en particular, la transmitida en los trabajos que hoy se reúnen con el nombre de Corpus hippocraticum (Tratados Hipocráticos), atribuidos a la escuela de Hipócrates de Cos (460 - 380 a.C.) ${ }^{1}$. Me ocuparé de algunos pasajes de la República que permiten afirmar no solo que su autor estaba familiarizado con esos textos, y con sus tesis principales, sino que se vale de ellas para ilustrar cuestiones de importancia filosófica.

Las referencias a la medicina en la obra de Platón son abundantes y de gran riqueza. Las menciones al médico griego Hipócrates en el Protágoras (311b) ${ }^{2}$ y en el Fedro (270c) han ayudado a los historiadores a precisar detalles biográficos del médico de Cos, y a estimar su fama entre sus contemporáneos. La profesión médica, en general, es también objeto de distintos pasajes en la obra del filósofo ateniense y es presentada, sobre todo, para señalar cuestiones de orden ético. Es el caso de la República, donde, hacia el inicio de la obra, Sócrates refiere que, así como la medicina "no busca lo conveniente para sí misma, sino para el cuerpo" (1.342c) $)^{3}$, el gobernante se debe a su súbdito y todo lo hace "mirando a éste y a su conveniencia y ventaja" (1.342e). La presencia en la filosofía platónica de esta dimensión deontológica de la práctica médica -manifiesta en la inclusión de conceptos como "salud" en la propuesta moral del autor de la República (Lidz)- llevó a Werner Jaeger a declarar que "sin exageración, puede afirmarse que la ciencia ética de Sócrates, que ocupa el lugar central en los diálogos de Platón, habría sido inconcebible sin el procedimiento de la medicina" (783). En ese mismo sentido, Fernández-Galiano se refiere a la tradicional denominación de la República como a remedial thing, esto es, como "un tratado de medicina política" (4).

En estas páginas, examino otra faceta -menos estudiada por la literatura especializada- de las relaciones entre la obra de Platón (la República en particular) y la medicina. Buscaremos en el texto del filósofo la

\footnotetext{
${ }^{1}$ Aunque, por convención, se atribuyen los Tratados a Hipócrates, no es claro cuáles textos son de su autoría y cuáles son obra de sus discípulos.

${ }^{2}$ En este diálogo, Sócrates, dirigiéndose a Hipócrates "hijo de Apolodoro y hermano de Fasón" (310a11), le habla de "tu homónimo Hipócrates, el de Cos, de los Asclepíadas" (311b7).

${ }^{3}$ Las citas de la República, cuando no se especifique su procedencia en el cuerpo del texto, vendrán precedidas por la abreviatura Rep.
} 
presencia de conocimientos técnicos de la ciencia hipocrática. En especial, nos concentraremos en los relativos a la llamada teoría humoral, que daba cuenta del origen y posible tratamiento de las enfermedades (Jouanna), explorando las referencias de Platón a ese modelo explicativo, propio del saber médico.

\section{La ciudad inflamada}

En esta sección estudio los conceptos de "ciudad inflamada" y de "sedición" en la República, su relación con los principios de la teoría humoral de la medicina hipocrática, y la importancia de ésta última en el tratamiento platónico de cuestiones relativas a la polis y al alma humana.

En el segundo libro de la República se describe el nacimiento de la ciudad. Esta surge de la asociación entre los hombres, que buscan suplir sus necesidades de alimento, habitación y vestido. Sócrates se refiere a esta ciudad como "sana" (2.373b3), caracterizada por la frugalidad y la moderación. Pero, con el tiempo, a partir de esta "ciudad sana" surge una "ciudad de lujo" (tryphôsa polis, 2.372e), donde entran en escena los excesos, la opulencia y la comida copiosa. Sócrates, al respecto, pregunta si "con ese (nuevo) régimen de vida, ¿tendremos, pues, mucha más necesidad de médicos que antes?", a lo que Glaucón contesta: "Mucha más" (2.373d).

Para describir la "ciudad de lujo" Sócrates emplea el adjetivo

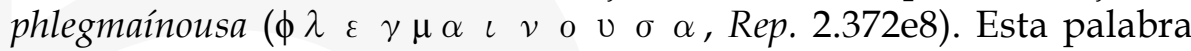
se ha traducido al español como "Estado afiebrado" (trad. Eggers Lan, 1988), y como "ciudad enferma" (trads. Divenosa y Márisco, 2005) o "atacada de una infección" (trads. Pabón y Fernández-Galiano, 2006). En el mismo sentido apuntan versiones en inglés como la de Joe Sachs (2007), que traduce "infected city" (ciudad infectada), y la de Allan Bloom (1968), quien opta por "feverish city" (ciudad febril o afiebrada). Tras examinar esas traducciones me permito formular una variante. Respecto del adjetivo "febril", el griego cuenta con la palabra pyretódis, más precisa para referirse a la fiebre. Por otro lado, "infectada" sería una traducción plausible si Platón hubiera utilizado alguna derivación del término míasma, que designaba los aires pútridos que, presumiblemente, podían transmitir enfermedades, y que tiene un significado aproximado al del latín infectio, usado también para hablar de "veneno" o "ponzoña". Pero, además de una imprecisión filológica, referirse a una "ciudad infectada" conduce a 
un anacronismo, pues el concepto contemporáneo de "infección" es propio del siglo XIX (López-Cerezo, 2008). Propongo que la palabra del español que mejor se adapta a phlegmaínousa es "inflamada" (o "hinchada"), -traducida, adecuadamente, por Mario Vegetti (1998) en el italiano "città infiammata".

La palabra griega phlegma $(\phi \lambda \varepsilon \gamma \mu \alpha)$, de la que proviene

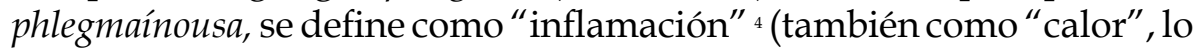
que pudo motivar su traducción por "febril"). Pero, en rigor, el vocablo significa "flema: uno de los cuatro humores en el cuerpo", es "un tipo de hidropesía, anasarca" y también un "humor maligno agriado", sinónimo de "pituita". Así, phlegmaínousa ( $\phi \lambda \varepsilon \gamma \mu \alpha \iota v$ o $v \sigma \alpha \alpha)$ significa "inflamada", pero también "pituitosa", "abundante en flema", y hace referencia a condiciones como la retención de líquidos (hidropesía) y a un edema generalizado (anasarca) .

La alusión a la palabra flema para describir el "Estado lujoso", nos reclama reseñar los fundamentos de la teoría humoral, característica de la escuela hipocrática y que, en virtud de su firmeza conceptual y de la lectura que de ella hiciera Galeno de Pérgamo (130-210 d-C.), se convirtió en "la única fundamentación nosológica de la medicina aceptada durante varios siglos" (Mejía Rivera 116). Aunque mencionada en varios de los Tratados, aparece en su versión completa en Sobre la naturaleza del hombre ${ }^{6}$, texto considerado una obra central de la doctrina escrita del médico de $\operatorname{Cos}^{7}$. Fue alimentada por el pensamiento de Alcmeón de Crotona -y su definición de la salud como el equilibrio de las cualidades del cuerpo o isonomía (i $\sigma$ o $v$ o o $\mu \hat{\imath} \alpha$ ) - y por las ideas de Empédocles de Agrigento, para quien la naturaleza estaba compuesta por cuatro elementos -agua, fuego, aire y tierra-, cada uno con cualidades particulares -humedad, calor, frío y sequedad,

\footnotetext{
${ }^{4}$ Las definiciones de este párrafo proceden de Liddell y Scott (1944-1945). Traducidas del inglés (cursivas en el original).

${ }^{5}$ El Gorgias habla de una ciudad "emponzoñada" e "infestada" (518e); aquí Platón usa otros dos términos provenientes de la medicina, oidein e hypolous, que traducen "hinchada" y "supurante".

${ }^{6}$ Los libros que componen el Corpus Hippocraticum se escribieron entre 420 y 350 a.C. Los textos citados en este ensayo son todos previos a 380 a. C. (fecha estimada de la escritura de la República); pero, dada la controversia que rodea la datación precisa de cada uno de los trabajos, aparecerán referidos con la fecha de publicación de su traducción al español. Algunas consideraciones sobre la datación de los originales pueden consultarse en Mendoza; López Eire; Vintró y García Gual. ${ }^{7}$ Según Galeno, este tratado fue escrito por el propio Hipócrates; Aristóteles lo consideró obra de su yerno y discípulo Pólibo. Es el libro en que se basan las menciones a la medicina en el Fedro (Smith). El término eîdos ("forma" o "idea"), usado en la República (3.402c2; 4.435b2), también procede de este texto.
} 
respectivamente- (Guerra; Laín Entralgo, La medicina; Grmek). La teoría humoral declara que el cuerpo está formado por cuatro humores, a saber: bilis amarilla, sangre, bilis negra y flema o pituita, de cuya mezcla armoniosa depende la salud, y cuya disarmonía conduce a la enfermedad. Las cualidades de los elementos de Empédocles aparecen aquí asociadas al carácter particular de cada uno de los humores: la bilis amarilla es seca y cálida, la bilis negra es fría y seca, la sangre, húmeda y cálida, y la flema (pituita) húmeda y frías.

Los Tratados hipocráticos insisten en que las enfermedades producidas por la flema (identificada como secreción mucosa y blanca) y las de la bilis (de color amarillento o negro), son las que más se distinguen entre sí. En Sobre los Humores, leemos que la bilis es caliente mientras que la flema es fría; "el verano resulta propicio para la bilis" (Hipócrates II.112) mientras la flema predomina en invierno, asociación que figura también en Sobre los aires, aguas y lugares (Hipócrates II). Las condiciones pituitosas producen la hinchazón y la plétora. Las enfermedades biliosas están asociadas a la fiebre y a la pérdida de líquidos corporales -fenómeno contrario al de la inflamación-, pues bajo el influjo de la bilis "los hombres sucumben en mayor grado a las disenterías, les mana sangre de la nariz y están más calientes y enrojecidos" (Hipócrates VIII.43).

Lo anterior refuerza la tesis según la cual la traducción más adecuada para phlegmainousa es "inflamada", antes que "febril", pues fiebre e inflamación son manifestaciones de procesos dominados por humores diferentes. La primera describe un estado de retención de líquidos (hinchazón), mientras la segunda se manifiesta en la evacuación abundante de secreciones. Esta distinción, entre los dos principales tipos humorales de la enfermedad, es referida por Platón cuando Sócrates menciona a ciertos individuos que como "zánganos" (Rep. 8.552c2), algunos con aguijón y otros sin él, perturban la ciudad "como la flema y la bilis perturban al cuerpo" (8.564c1-2). Para la medicina hipocrática, la fiebre y la inflamación eran dos caminos diferentes, y en cierta medida opuestos, por los que podía transitar una enfermedad

\footnotetext{
${ }^{8}$ La persistencia del número cuatro en los Tratados hipocráticos (el número de humores, de elementos y de estaciones del año), recuerda la importancia del número cinco en la obra de Platón: Eva Brann refiere, por ejemplo, las cinco modalidades (trópoi) del alma, los cinco eíde o géne mayores, los cinco planetas mencionados en el Timeo, entre otros.

${ }^{9}$ La mayoría de los tratados del Corpus hacen mención de la bilis sin especificar si se trata de su variante negra o amarilla. La expresión bilis negra (mélaina cholé) aparece en varios textos, pero su distinción de la bilis amarilla solo es explícita en Sobre la naturaleza del hombre.
} 
llegado su momento de crisis (krísis), entendido como una modificación súbita en el curso de un padecimiento -donde el cuadro clínico alcanza su mayor severidad-, tras la cual el enfermo podía, bien encaminarse hacia la curación, bien hacia el empeoramiento y la muerte (Laín Entralgo, La medicina 213).

La flema, asociada al elemento agua, también es descrita por Hipócrates como una propiedad de la comida capaz de llenar y atiborrar. En consecuencia, se asocia a la hidropesía por exceso de alimentos, a la inflamación, la lentitud y la apatía (Vintró 170). Está vinculada, también, con el fenómeno de stasis ( $\left.\begin{array}{cccc}\sigma & \alpha & \sigma & \iota\end{array}\right)$ o "detención", que es la obstrucción del flujo normal de los humores por la abundancia malsana de uno de ellos: el humor excesivo puede desplazarse a diferentes lugares del cuerpo (metástasis) o establecerse en un sitio distinto de su ubicación natural (apóstasis). El hombre "se enferma cuando alguno de los elementos se separa en mayor o menor cantidad en el cuerpo y no se mezcla con todos los demás" (Hipócrates VIII.37).

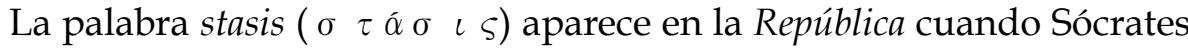
propone que la guerra contra otros pueblos helénicos se lleve con dignidad, respetando normas que no necesariamente se mantienen en las batallas contra los bárbaros ${ }^{10}$, y señala que "la enemistad en lo doméstico es llamada sedición (stasis); en lo ajeno, guerra (polemós)" (5.470b6). Cuando los griegos combaten entre ellos se dirá que "siguen siendo amigos por naturaleza, que con ello la Grecia enferma se divide y que esta enemistad ha de ser llamada sedición" (5.470d). Mientras polemós designa las disputas mantenidas con pueblos que no son griegos, stasis habla de una enfermedad del "cuerpo panhelénico", generada por la sublevación de alguno de sus componentes, similar a la que produce la detención de los humores en el organismo.

En la República aparece también la expresión pleonexia $(\varpi \lambda \varepsilon \circ \nu \varepsilon \xi i \alpha, 2.359 a)$ : la codicia ambiciosa de aquel que busca "prevalecer" (pleonekteîn) sobre los otros (Vallejo Campos 56) y que es la causa de la división malsana en el interior de la ciudad. La pleonexia es el origen de la enfermedad de la polis; la prevalencia de alguno de los humores lo es de la enfermedad del cuerpo. Estas referencias

\footnotetext{
${ }^{10}$ El griego "bárbaros" ( $\beta \bar{\alpha} \rho \beta \alpha \rho o \varsigma$ ) designaba todo aquel que no era parte de la polis, $\mathrm{y}$ las tribus que carecían de gobierno (Liddell y Scott 306).
} 
a la Teoría humoral permiten entender mejor el mal que aqueja a la "ciudad de lujo" que "sobrepasa el límite de cosas necesarias" (Rep. 2. 373d10): una ciudad enferma de hidropesía, víctima de la sedición de los elementos que la componen ${ }^{11}$.

La naturaleza del alma humana, en la filosofía de Platón, también tiene ecos del humoralismo médico. Así como según los hipocráticos los humores que conforman el cuerpo son cuatro, las partes del alma en la República son tres: la racional, la irascible o colérica y la concupiscible (4.434d-441c). Y así como cada uno de los humores tiene cualidades que le son propias, la sabiduría (o prudencia), el valor y la templanza son virtudes de cada una de las divisiones del alma y, a su vez, de los distintos estratos de la ciudad (en virtud de ello se habla del isomorfismo entre la constitución del hombre y la de la polis). La injusticia es la "sedición (stasis) de aquellos tres elementos, su empleo en actividades diversas y ajenas y la sublevación de una parte contra el alma toda" (Rep. 4.444b). En consecuencia

\begin{abstract}
el producir salud es disponer los elementos que hay en el cuerpo de modo que dominen o sean dominados entre sí conforme a naturaleza; y el producir enfermedad es hacer que se manden u obedezcan unos a otros contra naturaleza (...) la virtud será una cierta salud, belleza y bienestar del alma; y el vicio, enfermedad, fealdad y flaqueza de la misma (Platón, Rep. 4.444d-e).
\end{abstract}

\title{
Terapia hipocrática. La dietética
}

A continuación, revisaremos uno de los principios terapéuticos cardinales de la medicina hipocrática: la dietética, y su lectura crítica en el contexto de la República.

Los habitantes de la "ciudad sana" son vegetarianos. Esto apunta a dos cuestiones interesantes: la primera de orden ético, pues Platón nos muestra una ciudad cuyos pobladores no se alimentan de otros seres, no matan para vivir, lo que se relaciona con la moderación de

\footnotetext{
${ }^{11}$ Sócrates advierte que esa ciudad se llenará de una "plétora de imitadores" (2.373a), personajes como "poetas y sus auxiliares, tales como rapsodos, actores, danzantes y empresarios" (2.373b-c). Para la tradición hipocrática, la plétora (plesmóne) es una enfermedad de la abundancia-producto, precisamente, del exceso de flema- y se menciona en el tratado Sobre la dieta (III) como una consecuencia del consumo exagerado de alimentos.
} 
la fogosidad, la cual no debe predominar ni en el alma del hombre ni en la ciudad ideal. La segunda consideración es de orden higiénico ${ }^{12}$ : tratados hipocráticos como las Epidemias (1989) y los Aforismos (1983) se refieren insistentemente a la podagra ${ }^{13}$ (la artritis inflamatoria del grueso artejo del pie). Aunque el conocimiento de esta entidad es mucho más antiguo -aparece en escritos del siglo V a.C. (MacKenzie 183)- la de Hipócrates se considera la primera descripción completa de esa entidad (que hoy se conoce como gota) ${ }^{14}$, asociada con el consumo de carne y, en general, con la opulencia, y a la que el médico de Cos llama "la artritis de los ricos" (Iglesias-Gamarra et al. 121). El tratado Sobre la enfermedad sangrada (Hipócrates I) -célebre por defender que la epilepsia era, como las demás afecciones del cuerpo, producto de causas naturales y no sobrenaturales-, menciona que otros productos de origen animal, como el queso, pueden desencadenar la aparición de esta patología, pues tienen propiedades pro-inflamatorias (phlegmatódes). Así, la dieta de los habitantes de la "ciudad sana" responde, también, a las prescripciones de la medicina hipocrática, que relacionaba padecimientos como la podagra con los excesos en la alimentación, y en especial con la ingesta de carne ${ }^{15}$.

En el mismo sentido, en el libro tercero de la República Sócrates habla en contra de las "golosinas" (3.404c6) y de las "delicias de la pastelería ática" (3.404d7), y luego agrega:

Y el necesitar de la medicina -seguí- cuando no obligue a ello una herida o el ataque de alguna enfermedad epidémica, sino el estar, por efecto de la molicie o de un régimen de vida como el descrito, llenos, tal que pantanos, de humores o flatos, obligando a los ingeniosos Ascelpíadas a poner a las enfermedades nombres como "flatulencias" o "catarros", ¿eso no te parece vergonzoso? (Rep. 3.405d).

El fragmento anterior nos permite examinar varias cuestiones importantes en lo que respecta a la presencia de la medicina en la

\footnotetext{
${ }^{12}$ Léase en el sentido tradicional de la palabra, que incluye no solo cuestiones relativas a la limpieza sino a todas las prescripciones orientadas a conservar la salud.

${ }^{13}$ griego podos ("pie"), y agreos ("agarrar, atacar").

${ }^{14}$ El término "gota" aparecerá, por primera vez, alrededor del año 1200 d.C. en las obras de Geoffroi de Villehardouin.

${ }^{15}$ Cornelio Celso (26 a.C.- 50 d.C.), basado en los textos de la escuela de Cos, recomendaba, para prevenir la artritis, llevar una vida temperada y evitar la obesidad (1966).
} 
República. En primer lugar, la mención de la palabra "flatulencias" alude al texto Sobre los flatos, que argumentaba que los aires que penetraban en el cuerpo eran la causa de la enfermedad; de ahí el nombre del tratado, pues "el soplo que hay dentro de los cuerpos se llama flato, el que está fuera de los cuerpos es el aire" (Hipócrates II.134). Por su parte, la palabra "catarros" debe leerse no en su acepción contemporánea asociada con un resfriado común- sino pensando en el griego katárrous, término que Hipócrates acuñó para designar el flujo malsano de humores, secundario a un desequilibrio en el estilo de vida o en la dieta. Las alusiones a estos términos, de reciente aparición en tiempos de Platón, son una muestra más de que el filósofo conocía el vocabulario técnico de la escuela de Cos y sus connotaciones particulares.

En el mismo pasaje del tercer libro de la República, Sócrates critica la "terapéutica 'pedagógica' de las enfermedades" (3.406a5), que antes que curar rápidamente al paciente, indica una serie de cuidados permanentes de la salud. Con ello, se convierte en una tortura para el enfermo y lo conduce a "una muerte lenta" (3.406b4) puesto que debe dedicar toda su vida a atender su padecimiento. Sócrates prefiere las viejas prácticas de Asclepio ${ }^{16} \mathrm{y}$ sus descendientes, más coherentes con el "principio de especialización" (oikeiopragía) en virtud del cual cada uno realiza la tarea que le es propia: "en toda ciudad bien regida le está destinada a cada ciudadano una ocupación a la que ha de dedicarse forzosamente sin que nadie tenga tiempo para estar enfermo y cuidarse toda su vida" (Rep. 3.406c).

Para García Gual (1983), las prescripciones que son blanco de la crítica de Platón son las contenidas en el tratado Sobre la dieta (Hipócrates III), aunque una rápida mención a "Heródico" en el mismo fragmento de la República (3.406b8) hace pensar que el filósofo tenía en mente a Heródico de Selimbria, famoso por sus recomendaciones higiénicas para el tratamiento de las enfermedades. Su irrestricta aplicación de estas medidas le valió la burla del autor de Epidemias VI, quien relata que "Heródico mataba a los que padecían fiebres con largos paseos, con muchas luchas, con baños de vapor; mala cosa" (Hipócrates V §18, 224).

\footnotetext{
${ }^{16}$ Asclepio, personaje mítico, hijo del dios Apolo y la humana Corónide (Graves 257 - 263). Se lo menciona en la Ilíada como médico ilustre y padre de Podalirio y Macaón (IV, 198-219 ss). Su historia completa es narrada por Píndaro, en su Pítica III (1-60 ss). Hacia 500 a. C. fue encumbrado a dios de la medicina, y se popularizó la denominación "Asclepíada" para referirse, tanto a los sacerdotes que oficiaban en sus templos, como a los médicos en general (Kerény).
} 
En Sobre la naturaleza del hombre se lee que "las enfermedades surgen o de la dieta o del aire que inspiramos al vivir" (Hipócrates VIII.47) refiriéndose, en primer lugar, a los males que causan los excesos en la alimentación y la bebida y, en segundo lugar, a las epidemias, atribuidas a los "malos aires". Si la causa de la enfermedad es la abundancia y el desenfreno, ningún tratamiento será eficaz mientras las malas costumbres no se transformen. En consecuencia, la escuela de Hipócrates privilegiaba la dietética (no solo como un remedio para las enfermedades agudas sino como régimen para el cuidado permanente), especificando el tipo de alimentación que cada uno debía llevar, de acuerdo con las estaciones del año, con su constitución individual y con otros factores diversos. Estas medidas, en opinión de Sócrates, también convertían al usuario en esclavo de su enfermedad, a la que debía "seguir paso a paso" (Rep. 3.406b6). El filósofo prefiere remedios rápidos como "beber una pócima que le haga vomitar la enfermedad o que le libre de ella mediante una evacuación por abajo, un cauterio o una incisión" (Rep. 3.406d) y una medicina que, en lo referente a los enfermos crónicos, "no se consagra a prolongar y amargar su vida con un régimen de paulatinas evacuaciones e infusiones" (3.408d).

Sin embargo, aunque declara la futilidad de esas intervenciones, Sócrates se muestra de acuerdo con la máxima hipocrática según la cual la dieta y los buenos hábitos son indispensables para el mantenimiento de la salud ${ }^{17}$, y critica aquellos enfermos que solo agravan su condición al mantener un estilo de vida nocivo

\begin{abstract}
¿No es gracioso que tengan por su peor enemigo al que les dice la verdad, esto es, que, si no dejan sus borracheras, sus atracones, sus placeres amorosos y su ociosidad, ni las medicinas ni los cauterios ni las sajaduras ni tampoco los ensalmos ni los talismanes ni ninguna otra de tales cosas ha de servirles de nada? (Rep. 4.426b).
\end{abstract}

El interés de Platón a lo largo de la obra por promover un régimen que permita conservar la salud, señala la importancia que atribuye al cuerpo sano en la educación de los ciudadanos; en palabras de Werner Jaeger: "media una afinidad natural electiva entre la filosofía platónica y el cuerpo, a quien una educación rigurosa pone en posesión de

\footnotetext{
${ }_{17}$ Fernández-Galiano argumenta que el régimen de educación de los guardianes de la República es heredero de las prácticas higiénicas de la sociedad pitagórica de Crotona (18).
} 
una salud perfecta" (627). Esta atención a la dimensión física de los individuos es contraria a las lecturas de la filosofía platónica que la consideran orientada exclusivamente a lo suprasensible.

\section{Similia similibus curantur ${ }^{18}$}

Continuando nuestro estudio sobre la presencia de la terapéutica médica en la obra de Platón, este apartado examina la influencia del principio de similitud (fundamental en el Corpus Hippocraticum) en las consideraciones de la República respecto de la naturaleza del alma, y sus relaciones con la composición del Estado.

Sócrates, al referirse a la instrucción de los ciudadanos, señala que es natural que "partiendo de la educación en la dirección de la vida, todo lo que sigue sea como ella. ¿O no es cierto que lo semejante llama a lo semejante?" (4.425c). El autor de Sobre la naturaleza del hombre, ilustra un principio análogo que se conoce como principio de similitud o "principio de la curación por lo semejante", y menciona que "una vez que la vida del hombre llega a su fin, cada elemento vuelve a su naturaleza" (Hipócrates VIII.36), refiriéndose a los humores que retornan a los elementos que los determinan: dado que provienen de la tierra, el aire, el agua y el fuego, a ellos regresan después de la muerte del individuo. Esta afinidad natural es la causa de que en invierno predomine la flema, que es húmeda y fría, mientras que la sangre, caliente y húmeda, lo haga en verano. Este principio se aplicaba también a la terapéutica, pues "cuando el fármaco entra en el cuerpo, primero atrae aquel elemento del cuerpo más semejante a su naturaleza, después segrega y purga los demás" (41). Así mismo, para Sócrates, aquel que puede alcanzar la verdadera naturaleza de las cosas: "la alcanza con aquella parte de su alma a que corresponde, en virtud de su afinidad, el llegarse a semejantes especies, por medio de la cual se acerca y une a lo que realmente existe y engendra inteligencia y verdad" (Rep. 6.490b).

Tanto el cuerpo como el alma se rigen por el principio de similitud que aparece, nuevamente, en el libro X de la República cuando Sócrates declara que

\footnotetext{
${ }^{18}$ Expresión latina traduce "lo similar cura lo similar". Obedece al llamado principio de similitud, atribuido a Hipócrates (Nielsen, et al.).
} 
por la mala condición de los alimentos, sea ésta la que sea, ranciedad, putrefacción o cualquier otra, no pensamos que el cuerpo tenga que perecer, sino que, cuando la corrupción de estos alimentos ha hecho nacer en el cuerpo la corrupción propia de éste, entonces diremos que el cuerpo ha perecido con motivo de aquellos, pero bajo su propio mal, siendo éstos una cosa y el cuerpo otra y no habiendo sido producido el mal propio por el mal extraño, por esa causa jamás juzgaremos que el cuerpo haya sido destruido. (10. 609e-610a)

La enfermedad no puede generarse a partir de un elemento ajeno al cuerpo -en este caso por los alimentos en mal estado- sino que se produce, si bien por influjo de aquellos, por una perturbación en sus elementos propios, lo que en palabras de Hipócrates corresponde al desequilibrio de los humores". Sócrates se vale del principio similitud para afirmar, también, la inmortalidad del alma, pues, así como el cuerpo no puede enfermar o morir víctima de un mal que le sea ajeno

ni por la fiebre ni por otra cualquier enfermedad ni por el degüello ni aunque el cuerpo entero quede desmenuzado en tajos, ni aun así ha de perecer ni destruirse el alma en lo más mínimo; sostengámoslo hasta que alguno nos demuestre que por esos padecimientos del cuerpo se hace ella más injusta o impía. (10.610b)

Vinculada al "principio de la curación por lo semejante", los Tratados hipocráticos participan de una "idea naturalista" de la salud (Laín Entralgo, Antropología médica 181-182) según la cual ésta es sinónimo de equilibrio y armonía, y la enfermedad, por su parte, de disarmonía y perturbación de la buena mezcla (eukrasía). Esta idea se opone a las teorías "etiológicas" de la enfermedad que la atribuyen a causas exógenas. La mirada platónica sobre el alma y el Estado está influida por esa misma visión. La ciudad justa procede del equilibrio (la isonomía, en el pensamiento de Aclmeón) entre las distintas clases de hombres que la componen (los guardianes, los auxiliares y los artesanos o productores), al igual que el alma justa es aquella que goza de la armonía de sus partes constitutivas (racional, irascible y concupiscible). Así como se busca el equilibrio del cuerpo, se aspira al balance del alma, y del Estado, que manifiestan una estrecha correspondencia: “Fuerza será, por tanto, que el alma mala dirija y gobierne mal y que la buena haga bien 
todas estas cosas" (Rep. 1.353e). La injusticia, por su parte, sobreviene al desequilibrio. Para Platón y para Hipócrates, nada puede hacer mal al cuerpo, ni al alma o a la polis, excepto aquello que les es propio.

Vemos que la República se sirve de conceptos de la medicina (el equilibrio o desequilibrio de los humores, y el principio de similitud) que describen fenómenos del mundo sensible, para explicar argumentos relativos al alma humana (el balance necesario entre sus partes, y su condición inmortal) que pertenece a lo suprasensible. Este procedimiento responde a un principio heurístico que, junto con otra alusión a la ciencia médica, podemos leer en el Fedro,

Sócrates: ¿crees que es posible comprender adecuadamente la naturaleza del alma si se la desgaja de la naturaleza en su totalidad?

Fedro: si hay que creer a Hipócrates el de los Asclepíadas, ni siquiera la del cuerpo sin este método. (270c)

\section{Medicina para la ciudad}

Esta sección se ocupa, en primer lugar, de la influencia del Corpus Hippocraticum en la propuesta platónica de una "cura" para la ciudad injusta, su relación con tratamientos médicos como la evacuación (kátharsis), y sus consideraciones respecto del uso de fármacos. En segundo lugar, se explora el papel de la mentira - que la República define como un medicamento - y de la mirada hipocrática sobre el cuerpo humano (entendido como uno e indivisible), en la invitación de Platón a una necesaria unidad de la polis. Finalmente, se hacen algunas anotaciones en torno a la que podemos llamar la "crisis de la República".

\section{Si la naturaleza no sana: una purga terapéutica}

Una idea central de la terapia hipocrática está representada en las palabras latinas vis medicatrix naturae (el poder sanador de la naturaleza). La naturaleza (physis), por sí misma, se orienta a la curación, y es deber de la medicina, inicialmente, apenas facilitar ese proceso, sobre todo a través de medidas higiénicas. La naturaleza es "ordenada en sí misma y ordenadora desde dentro de sí misma" (Laín Entralgo, La medicina 54); a ello se atribuye su tendencia a la salud. Sin embargo, cuando los desarreglos son profundos, la acción del médico debe ser más impetuosa, 
y es cuando recurre a los fármacos. Esta idea tiene eco en varios pasajes de la República, por ejemplo, cuando Sócrates declara que

\begin{abstract}
cuando el cuerpo no necesita de remedios, sino que se presta a someterse a un régimen, consideramos, creo yo, que puede bastar incluso un médico mediano. Pero, cuando hay que recurrir también a las drogas, sabemos que hace falta un médico de más empuje. (4.459c)
\end{abstract}

Este pasaje no solo señala la afinidad del filósofo con el principio del "poder sanador de la naturaleza"; también subraya la necesidad de contar con guardianes capaces de enfrentar la enfermedad de la ciudad: “El que está enfermo, sea rico o pobre, tiene que ir a la puerta del médico, y todo el que necesita ser gobernado, a la de aquel que pueda gobernarlo" (Rep. 6.489c-d). La República define a los guardianes con la misma palabra usada por los griegos para referirse a sus médicos: demiourgós, "funcionarios al servicio de la comunidad" (García Gual 12).

La ciudad, gravemente enferma, necesita tratamiento. Sea la "ciudad de lujo" que debe ser "purificada" (3.339e5), o aquella que ha degenerado en la timocracia, la oligarquía, la democracia o la tiranía, sistemas estos que Mario Vegetti denomina "los cuadros clínicos de la enfermedad de las ciudades" (117) ${ }^{19}$. La educación de los miembros de la polis, de conformidad con la justicia, es la terapia requerida. Pero el tratamiento empieza por sacar de la ciudad todo lo dañino: los filósofos "tendrán que coger, como se coge una tablilla, la ciudad y los caracteres de los hombres y ante todo habrán de limpiarla" (Rep. 6.501a). Este proceso, llamado por Vegetti "una catarsis del cuerpo social, una purga terapéutica" (118), es necesario para después inculcar nuevos saberes. Al respecto, leemos en la República que "así mismo, para curar la ciudad y a cada una de sus almas es preciso abandonar los vicios antes que legislar sobre particulares sin extirpar las causas de la enfermedad, con lo que a lo sumo se acaban cortando las cabezas de la hidra" (4.426e9).

\footnotetext{
${ }^{19}$ La República describe que el hombre, en virtud de su isomorfismo con la ciudad, es por naturaleza timocrático, oligárquico, democrático o tiránico. La idea de la existencia de temperamentos, determinados por los mismos cuatro humores de la medicina griega (flemático, colérico, sanguíneo y bilioso), es posterior al Corpus hippocraticum, aunque en los Tratados, la bilis negra (mélaina chole) sí aparece vinculada con la apatía y la tristeza. Warren Lidz señala que la palabra thymoeidés $(\theta \cup \mu$ o $\varepsilon \iota \delta \eta \varsigma)$-que traduce "irascible" o "fogoso"- aparece primero en Sobre las Aguas, los aires y los lugares, y luego es apropiada por Platón para denotar el temperamento característico de los guardianes (529).
} 
La necesidad de esta purga alude, de nuevo, al uso del adjetivo phlegmaínousa (descrito en la primera sección de este trabajo) en referencia al predominio del humor flemático para describir el mal que aqueja a la ciudad, pues "cuantas enfermedades causa la plétora, las cura el vaciamiento" (Hipócrates VIII.46). El autor de Sobre las Afecciones recomienda que, si la enfermedad pituitosa es leve, puede tratarse por medio de la dieta, "pero si no se libra, purgar la cabeza de flema" (III. §2, 143). La mayoría del Corpus hippocraticum utiliza la palabra fármaco (phármakon) para designar, exclusivamente, los tratamientos purgantes, esto es, que favorecen la catarsis (kátharsis), entendida no solo como la evacuación (purga) de los humores malsanos sino en el sentido general de kathairein: la "acción de purificar" (Laín Entralgo, La medicina 327 - 329).

\section{La mentira como fármaco. La unidad del cuerpo}

La República se refiere a la llamada "mentira noble" (gennaîon pseûdos, 3.414c1) como un "medicamento" (phármakon, 2.382c10; 3.389b4). Así como los fármacos son empleados por el médico, en virtud de su conocimiento del cuerpo sano y enfermo, y no deben dejarse al arbitrio de los legos, la potestad de mentir, con fines ilustres, debe quedar solo a disposición de los guardianes, formados para conocer el tratamiento adecuado para la ciudad
porque si no nos engañábamos hace un momento y realmente la mentira es algo que, aunque de nada sirve a los dioses, puede ser útil para los hombres a manera de medicamento, está claro que una semejante droga debe quedar reservada a los médicos sin que los particulares puedan tocarla. (3.389b)

La "mentira noble" aparece en la República como una terapia dirigida a fomentar la autoctonía, el sentimiento de unidad de todo el cuerpo de la polis. Es el caso del "mito de los terrígenas", que inculca en todos los ciudadanos la creencia de que brotaron, literalmente, de la misma tierra griega. Usada "en calidad de medicina" (5.459d1), la mentira tiene por objeto la conformación de lo que Sócrates llama una "comunidad corporal" (5.462c13) donde las alegrías y penas de una de sus partes se experimentan como propias por toda la comunidad 
toda ella siente y toda ella sufre a un tiempo y en su totalidad al sufrir de una de sus partes; y así decimos que el hombre tiene dolor en un dedo. ¿Se puede decir lo mismo acerca de cualquier otra parte de las del hombre, de su dolor cuando sufre un miembro y su placer cuando deja de sufrir? (Rep. 5.462d)

El mal de uno de sus miembros debe sentirse como mal de todo el "cuerpo del Estado", así como el dolor de una parte es percibido por todo el organismo. No solo la ciudad es una sola, también lo es el alma humana: aunque, en principio, sea presentada por Sócrates como tripartita, goza de la misma unidad que se predica del Estado. Un principio análogo caracteriza la medicina hipocrática, pues, aunque ésta se fundamenta en el equilibrio de los humores, estos siempre componen un cuerpo único e indivisible. En Sobre los lugares en el hombre se lee un pasaje de gran similitud con las palabras de Platón, citadas renglones arriba

si alguien intenta, cogiendo la parte más pequeña del cuerpo, provocar un daño, todo el cuerpo se resentirá de este mal, cualquiera que sea. La razón es la siguiente: La parte más pequeña del cuerpo posee todo lo que también posee la más grande. Lo que padece, sea lo que sea, lo transmite la parte más pequeña a todo lo que tiene su misma naturaleza y su mismo origen, tanto si es bueno, como si es malo (Hipócrates, VIII. \$1, 90-91).

Para Sócrates, la ciudad justa es "un cuerpo que participa del placer y del dolor de cada uno de sus miembros" (Rep. 5.464b 2-3). La felicidad de un grupo particular, por ejemplo, la de los guardianes, no es el objetivo principal de la ciudad que propone la República (aunque hacia el final del libro se demuestra que, en efecto, quien es justo es feliz). Por el contrario, el filósofo enfatiza que "nosotros no estableceremos la ciudad mirando a que una clase de gente sea especialmente feliz, sino para que lo sea en el mayor grado posible la ciudad toda" (4.420b). El mayor bien para la ciudad es ser una y no muchas (5.462 a-b), al igual que el cuerpo sano es aquel que no se disgrega en sedición.

Una consideración final respecto de la salud de la polis: en la primera sección de este texto señalé que, de acuerdo con la tradición hipocrática, la crisis ( $\kappa \rho 10$ í $\sigma$ ) es el momento en que una enfermedad alcanza 
su máxima severidad, y que de este punto bien pueden seguirse el empeoramiento y la muerte, o la curación. Para el autor de Sobre las afecciones "hay crisis en las enfermedades cuando éstas o se hacen mayores o decrecen, o se transforman en otras enfermedades, o desaparecen" (III. §8, 148). En los libros VIII y IX de la obra de Platón, se menciona la que podemos llamar, con William Altman (2012), la "crisis de la República". Se ilustra la degeneración sucesiva de los hombres y de las formas de gobierno, y se argumenta que la democracia es el sistema que, precisamente, puede caer más fácilmente en la tiranía, definida como la peor "enfermedad del Estado" (8.544c9). Pero es la democracia, también, el sistema que

\begin{abstract}
reúne en sí toda clase de constituciones, y al que quiera organizar una ciudad, como ahora mismo hacíamos nosotros (se refiere Sócrates a sí mismo y a sus interlocutores), es probable que le sea imprescindible dirigirse a un Estado regido democráticamente para elegir en él, como si hubiese llegado a un bazar de sistemas políticos, el género de vida que más le agrade $y$, una vez elegido, vivir conforme a él. (8.557d)
\end{abstract}

De acuerdo a la medicina hipocrática, la crisis, a pesar de exhibir una mayor severidad del cuadro clínico, representa la mejor posibilidad para la curación del paciente. De igual manera, la democracia, sistema que para Platón amenaza con llevar a la crisis del Estado, es al mismo tiempo el único en el que son posibles la libre elección, la deliberación, la filosofía y, a través de ella, la curación de la ciudad enferma.

\title{
Conclusión
}

He señalado algunas relaciones entre el pensamiento de Platón, en particular el contenido en la República, y la medicina hipocrática. He puesto el énfasis en la teoría humoral de la enfermedad y su importancia capital en la construcción de los argumentos del filósofo ateniense, además de visitar propuestas terapéuticas como la dietética, el principio de similitud, el uso de fármacos purgantes, y su lectura platónica a la luz de una necesaria "medicina para la ciudad". Podemos concluir que los saberes médicos, antes que conocimientos marginales, tienen un papel central en el discurso que el diálogo presenta, y muestran una recepción crítica de los contenidos del Corpus Hippocraticum por parte del autor de la República. Estos puentes conceptuales contribuyen a la 
comprensión de la obra del filósofo, quien no solo muestra un dominio de los conceptos propios de la ciencia médica de su tiempo, sino que logra incorporarlos a su filosofía, valiéndose de ellos para ilustrar su compromiso con la justicia y con la salud de la ciudad y del alma humana.

\section{REFERENCIAS}

Altman, William H. F. Plato the Teacher. The Crisis of the Republic. Lexington Books, 2012.

Brann, Eva. La música de la República. Ensayos sobre las conversaciones de Sócrates y los escritos de Platón. Universidad de Valencia (PUV), 2015.

Celso, Aulo Cornelio. Los ocho libros de la medicina, volumen 1. Iberia, 1966.

Fernández-Galiano, Manuel. “Introducción. La génesis de ‘La República'”. República, Platón, Trads. José Manuel Pabón y Manuel Fernández-Galiano. Centro de Estudios Políticos y Constitucionales, 2006, pp. 1 - 23.

García Gual, Carlos. "Introducción general". Tratados hipocráticos. Volumen I: Juramento; Ley; Sobre la ciencia médica; Sobre la medicina antigua; Sobre el médico; Sobre la decencia; Aforismos; Preceptos; El pronóstico; Sobre la dieta en las enfermedades agudas; Sobre la enfermedad sagrada, Hipócrates. Gredos, 1983, pp. 9 - 61.

Graves, Robert. Los Mitos Griegos, Volumen 1. Alianza, 1985.

Grmek, Mirko. Diseases in the Ancient Greek World. John Hopkins University Press, 1983.

Guerra, Francisco. Historia de la Medicina. Tomo I. Norma, 1982.

Hipócrates. Tratados hipocráticos. Volumen I: Juramento; Ley; Sobre la ciencia médica; Sobre la medicina antigua; Sobre el médico; Sobre la decencia; Aforismos; Preceptos; El pronóstico; Sobre la dieta en las enfermedades agudas; Sobre la enfermedad sagrada. Gredos, 1983.

---. Tratados hipocráticos Volumen II: Sobre los aires, aguas y lugares; Sobre los humores; Sobre los flatos; Predicciones I; Predicciones II; Prenociones de Cos. Gredos 1986. 
---. Tratados hipocráticos Volumen III: Sobre la dieta; Sobre las afecciones; Apéndice a "Sobre la dieta en las enfermedades agudas"; Sobre el uso de los líquidos; Sobre el alimento. Gredos, 1986.

---. Tratados hipocráticos Volumen V: Epidemias. Gredos, 1989.

---. Tratados hipocráticos Volumen VIII. Sobre la naturaleza del hombre; Lugares en el hombre; Carnes; Corazón; Naturaleza de los huesos; Generación; Naturaleza del niño; Enfermedades IV; Parto de ocho meses; Parto de siete meses; Dentición; Visión; Glándulas; Anatomía; Semanas; Crisis; Días críticos; Remedios; Juramento II. Gredos, 2003.

Homero. Ilíada (14 ed. revisada). Trad. Antonio López Eire. Cátedra, 2008.

Iglesias-Gamarra, Antonio., Quintana, Gerardo y Restrepo Suárez, José Félix. "Prehistoria, historia y arte de la Reumatología, Gota y espondilitis anquilosante". Revista colombiana de reumatología, 2006:13,2, pp. 120-141. https://www.researchgate.net/publication/237348603_ Prehistoria_historia_y_arte_de_la_Reumatologia_Gota_y_ espondilitis_anquilosante

Jaeger, Werner. Paideia: los ideales de la cultura griega. Fondo de Cultura Económica, 2008.

Jouanna, Jacques. "The Legacy of the Hippocratic Treatise the Nature of Man: the theory of the four humours". Greek Medicine from Hippocrates to Galen: Selected Papers J. Jouanna editor. Brill, 2012, pp. 335 - 360.

Kerényi, Karl. El Médico Divino. Imágenes primigenias de la religión griega. Sexto Piso, 2008.

Laín Entralgo, Pedro. La medicina hipocrática. Revista de Occidente, 1970.

---. Antropología médica, para clínicos. Salvat, 1984.

Liddell, Henry y Scott, Robert. Greek - English Lexicon. Clarendon Press, 1996.

Lidz, Joel Warren. "Medicine as metaphor in Plato". The Journal of Medicine and Philosophy, 1995: 20, pp. 527-541. https://doi. org/10.1093/jmp/20.5.527 
López Eire, Antonio. “En torno a la lengua del Corpus Hippocraticum”. Emerita, 1984: 52, 2, pp. 325 - 354. https://doi.org/10.3989/ emerita.1984.v52.i2.705

López-Cerezo, José Antonio. El triunfo de la antisepsia. Un ensayo en filosofía naturalista de la ciencia. Fondo de Cultura Económica, 2008.

MacKenzie, Ronald. "Gout and Hyperuricemia: an Historical Perspective". Current Treatment Options in Rheumatology, 2015: 1, 2, pp. 119-130. https:// doi.org/10.1007/s40674-015-0012-9

Mejía Rivera, Orlando. La medicina antigua. De Homero a la peste negra. Universidad de Caldas, 2017.

Mendoza,Julia.“Aportaciones delestudiodelalenguaaladeterminación de la cronología de dos tratados del Corpus Hippocraticum". Emerita, 1976: 44, 1, pp. 171 - 188. Digital.

Nielsen, Tove Kjolhede., Frederiksen, Line., Ventegodt, Soren y Joav Merrick. "Similia similibus curentur in nonpharmaceutical medicine. The use of Hippocrates' healing principle of similarity in clinical holistic medicine: controlled violence and sexual abuse in holistic mind-body medicine". International Journal on Disability and Human Development, 2009: 8, 3, pp. 219-226. https://doi.org/10.1515/IJDHD.2009.8.3.219

Píndaro. Píticas. Trad. Alfonso Ortega. Gredos, 2011.

Plato. Republic. Trad. Allan Bloom. Basic Books, 1968.

---. Republic. Trad. Joe Sachs. Focus Publishing, 2007.

---. Diálogos. Volumen III. Fedón, Banquete, Fedro. Gredos, 1988.

---. República, Trads. Marisa Divenosa y Claudia Márisco. Losada, 2005.

---. República. Trad. Conrado Eggers Lan. Gredos, 1988.

---. República. Trads. José Manuel Pabón y Manuel Fernández-Galiano. Centro de Estudios Políticos y Constitucionales, 2006.

---. Diálogos. Volumen I. Apología, Critón, Eutifrón, Ion, Lisis, Cármides, 
Hipias menor, Hipias mayor, Laques, Protágoras. Gredos, 1985.

---. La Repubblica. Trad. Mario Vegetti. Bibliopolis - Elenchos, 1998.

Smith, Wesley. The Hippocratic Tradition. Cornell University Press, 1979.

Vallejo Campos, Álvaro. Adonde nos lleve el Logos. Para leer la República de Platón. Trotta, 2018.

Vegetti, Mario. Quince lecciones sobre Platón. Gredos, 2012.

Vintró, Eulalia. Hipócrates y la nosología hipocrática. Ariel, 1972. 